\title{
Norma Técnica de Padronização e as Delegacias das Mulheres em Santa Catarina
}

\author{
Ana Claudia Delfini Capistrano de Oliveira
} Ana Silvia Serrano Ghisi

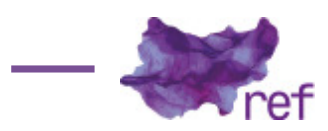

Resumo: O artigo apresenta os resultados de uma pesquisa realizada com delegados/as que atuam nas Delegacias Especializadas de Atendimento às Mulheres em 19 regiões de Santa Catarina. Os objetivos principais foram compreender o perfil dos delegados/as e analisar a adequação das atividades policiais e das condições estruturais administrativas das Delegacias em relação à Norma Técnica de Padronização das Delegacias Especializadas de Atendimento à Mulher. A abordagem metodológica apoia-se em dados quantitativos obtidos com a utilização de um questionário online, respondido pelos delegados/as. Os resultados da pesquisa mostram que as delegacias são majoritariamente comandadas por delegados homens, que as condições estruturais e atividades executadas nas referidas unidades policiais estão aquém do previsto na Norma.

Palavras-chave: Violências de Gênero; Norma Técnica; Delegacia da Mulher

Technical Norm of Standardization and Women's Police Station in Santa Catarina

Abstract: The article presents the results of a research done with delegates who work in the Women's Police stations for Assistance to Women in 19 regions of Santa Catarina. The main objectives were to understand the profile of the delegates, to analyze the adequacy of the police activities and the administrative structural conditions of the Police Stations in relation to the Technical Norm of Standardization of the Women's Police Station for Assistance to Women. The methodological approach is based on quantitative data obtained through the use of an online questionnaire answered by delegates. The results of the research indicate that the Police Stations are mostly commanded by men delegates, that structural conditions and the activities carried out in Police Station units fall short of the provisions of the Technical Norm.

Keywords: Gender Violence; Technical Norm; Women's Police Station

\section{Introdução}

A violência contra as mulheres é um fenômeno histórico-cultural atravessado por indicadores sociais relacionados à origem étnica, classe social, gênero e geração e requer do Estado uma abordagem intersetorial para seu enfrentamento. Este enfrentamento deve ser efetuado mediante uma política integral de atendimento, com foco na prevenção e assistência às mulheres, uma vez que as políticas de enfrentamento à violência contra mulheres ainda se mostram bastante frágeis na redução dos índices de violência.

Em vigor desde 07 de agosto de 2006, a Lei Maria da Penha trouxe inovações no tema do enfrentamento à violência doméstica e familiar, desde a concepção de gênero na própria definição de violência até suas classificações nos âmbitos físico, sexual, psicológico, moral e patrimonial. Com a vigência dessa Lei, regulamentou-se a Política Nacional de Enfrentamento à Violência contra Mulheres.

Segundo o Mapa da Violência, por Julio Jacobo Waiselfisz (2015), entre 2003 e 2013, o número de morte de mulheres foi de 4.762 , um aumento de $21 \%$ para esta década, com uma taxa de mais de 50 mil feminicídios, cujos autores foram parceiros ou ex-parceiros das mulheres. 
Dados alarmantes também são verificados pela Central de Atendimento à Mulher, que registrou, para o primeiro semestre de 2016,555.634 atendimentos que equivalem a uma média de 92.605 atendimentos por mês, numa estimativa de $12,23 \%$ de relatos de violência sendo $50 \%$ deles ligados à violência física. (SNPM, Secretaria Nacional de Políticas para as Mulheres, 2016, p.3)

Tais índices mostram que o enfrentamento das violências contra a mulher necessita da composição institucional de medidas de integração entre os Poderes e os Entes da Federação, por meio de diversos instrumentos jurídicos de caráter protetivo, que consolidem uma política de prevenção e assistência à mulher em situação de violência. Um desses instrumentos é a Lei Maria da Penha, fruto de um contexto amplo de luta e reivindicação feminista e de um esforço coletivo de organização de políticas de gênero, que resultou na elaboração dos Planos Nacionais de Políticas para Mulheres e nas políticas públicas de enfrentamento às violências.

A lei Maria da Penha demandou novas atribuições policiais, sobretudo em relação às ações que deverão ser executadas pela autoridade policial para garantir proteção à mulher, desde o primeiro atendimento até à possibilidade de solicitação de medidas protetivas e/ou a decretação de prisão preventiva. É importante ressaltar que as atribuições das Delegacias Especializadas de Atendimento às Mulheres demandaram a elaboração de uma diretriz para a estruturação das unidades policiais. Por iniciativa da Secretaria Nacional de Segurança Pública e da Secretaria de Políticas para Mulheres, foi elaborada a "Norma Técnica de Padronização das Delegacias Especializadas de Atendimento às Mulheres - DEAMs", foco do presente artigo.

Este artigo apresenta uma análise sobre as atribuições legais específicas da Polícia Civil, regulamentadas pela Norma Técnica de Padronização das Delegacias Especializadas de Atendimento à Mulher, a partir dos resultados de uma pesquisa realizada com delegados e delegadas que atuam nas Delegacias Especializadas de Atendimento às Mulheres em 19 regiões de Santa Catarina.

A pesquisa teve por objetivo compreender o perfil dos delegados e delegadas atuantes nas delegacias selecionadas, o conhecimento acerca das atribuições, procedimentos e diretrizes preconizadas na Norma Técnica, bem como sua adequação às atividades policiais e às condições estruturais administrativas preconizadas pela Norma.

A abordagem metodológica apoia-se em dados quantitativos obtidos com a utilização de um questionário online, respondido pelos delegados e delegadas. Os procedimentos metodológicos consistiram em duas etapas: a análise documental das atribuições legais da Polícia Civil e das atividades exigidas da Polícia, constantes da Norma Técnica de Padronização das Delegacias Especializadas de Atendimento à Mulher, descritas na primeira parte deste artigo. A segunda etapa foi a elaboração, pelas pesquisadoras, de um questionário com perguntas fechadas e abertas ${ }^{1}$ concernentes às atribuições, procedimentos e diretrizes preconizadas na Norma Técnica a respeito das atividades policiais e das condições estruturais administrativas.

\section{Política civil e organização policial em Santa Catarina}

Se a violência contra as mulheres é uma forma de expressão das históricas assimetrias de gênero, que revelam suas hierarquias e formas de dominação masculina, um dos campos mais expressivos de enfrentamento às violências está no interior do próprio Estado e das políicas públicas, como as delegacias especializadas de atendimento às mulheres, que "podem servir como nós articuladores desses campos. " (Sonia ALVAREZ, 2014, p. 19)

A Constituição Federal de 15 de outubro de 1988, no artigo 144, prevê a Segurança Pública como sendo "dever do Estado, direito e responsabilidade de todos" sendo exercida "para a preservação da ordem pública e da incolumidade das pessoas e do patrimônio" (BRASIL, 1988). 0 referido artigo traz, ainda, um rol de órgãos que exercerão a Segurança Pública: Polícia Federal, Polícia Rodoviária Federal, Polícia Ferroviária Federal, Polícias Civis, Polícias Militares e Corpos de Bombeiros Militares. À Polícia Civil coube a missão constitucional de exercício das funções de polícia judiciária e apuração das infrações penais, exceto as de competência da Polícia Federal e as infrações penais militares. O texto da Constituição Federal prevê, ainda, que as Polícias Civis serão dirigidas por delegados de polícia de carreira e se subordinarão aos Governadores dos Estados.

É importante lembrar que a lei federal n. 10.826, de 22 de dezembro de 2003, instituiu o Sistema Nacional de Armas no Ministério da Justiça, no âmbito da Polícia Federal, a qual passou a ter competência em todo o território nacional para controle da propriedade e uso de armas e munições. Portanto, a Polícia Civil deixou de possuir esta atribuição. Com relação à supervisão de serviços de segurança privada, a Lei 7.102, de 20 de julho de 1983, autorizava que o Ministério da Justiça efetuasse convênio com as Secretarias de Segurança Pública dos Estados para supervisionar tais atividades.

'Nas perguntas abertas, indagou-se a compreensão acerca das percepções de gênero por parte dos delegados e delegadas e as demandas relacionadas à violência de gênero atendidas pelas Deams. No entanto, por recorte temático, a análise de tais questões não faz parte do escopo deste artigo. 
A Lei 9.017 , de 30 de março de 1995, entretanto, modificou a legislação anterior e passou a atribuir à Polícia Federal a exclusividade para normatização, controle e fiscalização das atividades de segurança privada. Restaram à Polícia Civil, portanto, as atividades relativas à execução dos serviços de polícia judiciária, apuração das infrações penais, supervisão dos serviços de trânsito e fiscalização de jogos e diversões públicas. Desta forma, percebe-se que, além das funções investigativas, algumas atribuições de polícia administrativa ficaram a cargo da Polícia Civil, em razão da tradição histórica que sempre atribuiu a este órgão as funções de polícia judiciária e polícia administrativa.

Embora a Constituição Federal tenha atribuído às polícias suas funções precípuas, ela não impediu o exercício de polícia administrativa pelos órgãos policiais, no que for relacionado à preservação da ordem pública. Em que pese esse entendimento, alguns autores consideram a Polícia Civil como órgão meramente repressivo, e que deveria atuar somente a partir da ocorrência de um crime:

Tão logo o autor de um delito seja contido após o cometimento do ilícito, ou mesmo que não se conheça o autor, mas havendo quebra da ordem, o assunto passa a ser, de fato e de direito, da polícia judiciária. [...] De qualquer forma, em havendo a atuação da policial judiciária, os atos serão regidos pelo Direito Processual Penal, sob a égide do Poder Judiciário como destinatário final da investigação, bem como do controle externo do Ministério Público. Esta fase é iniciada como Auto de Prisão em Flagrante ou a instauração do Inquérito Policial (comum ou militar). (João Schorne de AMORIM, 2009: p.123)

Esta posição pode ser correta quando se fala na atividade policial visando somente a restauração da ordem pública violada, ou seja, a partir da ocorrência do crime e objetivando sua punição no âmbito judicial. Por outro lado, quando se fala em missão de preservação da ordem pública, que é a atividade atribuída a todos os órgãos da segurança pública listados no artigo 144 da Constituição Federal, a atuação policial civil deve superar a atitude meramente repressiva.

Em Santa Catarina, os órgãos da Polícia Civil e Militar encontram-se subordinados à Secretaria de Estado de Segurança Pública, juntamente com o Corpo de Bombeiros Militar, o Instituto Geral de Perícias e o Departamento Estadual de Trânsito. A organização administrativa dessa Secretaria é prevista na Lei complementar estadual n. 381/2007, com as modificações instituídas pela Lei Complementar n. 534, de 20 de abril de 2011.

A Polícia Civil de Santa Catarina está presente em todo o território estadual, organizada em Diretorias de Polícia, Delegacias Regionais de Polícia, Delegacias de Comarca e Delegacias de Município. As atribuições das referidas unidades estão disciplinadas no Decreto Estadual n. 4.141, de 23 de dezembro de 1977.

As Delegacias de Comarca (DPCOs) são instaladas de acordo com as sedes de comarcas judiciais, conforme definição do Código de Divisão e Organização Judiciárias do Estado de Santa Catarina. Por exclusão, nas cidades que não são sedes de comarcas, as delegacias se denominam Delegacias de Polícia de Município (DPMUs) e se subordinam, administrativamente, à DPCO. Tanto as DPCOs como as DPMUs compõem regiões policiais, sendo subordinadas às Delegacias Regionais de Polícia (DRPs). Essas DRPs coordenam administrativamente as DPCOs e DPMUs, além de congregarem serviços de expedição de documentos de trânsito, documentos de identificação e alvarás de jogos e diversões públicas. Atualmente, são 30 DRP que se subordinamse às Diretorias de Polícia.

Na estrutura catarinense há, ainda, uma Diretoria Estadual de Investigação Criminal (DEIC), e a Diretoria de Inteligência, ambas com atribuição para atuação em todo o Estado. Todas as Diretorias, juntamente com a Academia da Polícia Civil (órgão de ensino e pesquisa) e a Corregedoria (órgão correcional), estão subordinadas ao Gabinete do Delegado Geral.

As atividades de polícia civil são exercidas por quatro carreiras distintas previstas no Plano de Carreira da Polícia Civil catarinense, a Lei Complementar n. 453/2009: O primeiro cargo é o de agente de Polícia, cujas atribuições estão relacionadas à função investigativa criminal, de polícia judiciária e de polícia administrativa com ênfase na atuação preventiva. Entretanto, não há qualquer referência específica ao atendimento às mulheres em situação de violência doméstica e familiar para os profissionais dessa carreira.

O segundo cargo é a carreira de Escrivão de Polícia Civil, ao qual compete a lavratura dos procedimentos de polícia judiciária (auto de prisão em flagrante, inquérito policial e termo circunstanciado), além de outros termos específicos durante o procedimento investigativo (termo de apreensão, termo de reconhecimento, por exemplo)

Assim como para o cargo de Agente de Polícia Civil, não há qualquer referência específica à lavratura de procedimentos referentes ao enfrentamento à violência contra a mulher. Esses procedimentos constam na descrição de atividades dos psicólogos policiais, na qual encontrase as primeiras referências ao atendimento especializado de vítimas em situação de vulnerabilidade, como crianças, adolescentes e mulheres. 
O terceiro cargo, de psicólogo policial, é uma carreira que só existe na Polícia Civil catarinense. Inicialmente, a carreira se destinava ao trabalho junto às questões de trânsito, atuando nos exames psicotécnicos do Departamento Estadual de Trânsito, que pertencia à estrutura da Polícia Civil. Entretanto, a carreira passou por significativas mudanças, constituindo-se em importante corpo técnico a serviço da segurança pública e também dos próprios policiais civis.

A última carreira refere-se às atribuições do cargo de delegado de polícia como servidor responsável por "planejar, programar, organizar, dirigir, coordenar, supervisionar e controlar as atividades de polícia judiciária, de apuração de infrações penais e de polícia administrativa, no âmbito das suas atribuições constitucionais e legais." (SANTA CATARINA, 2009, p.1)

São os delegados e delegadas de polícia os responsáveis, constitucionalmente, por dirigirem as Polícias Civis, possuindo diversas atribuições relacionadas à coordenação administrativa das unidades policiais, coordenação das atividades investigativas e condução dos procedimentos de polícia judiciária, além de expedir alvarás e atestados, relacionados à atividade de polícia administrativa.

No organograma da Polícia Civil de Santa Catarina, não se encontram especificadas as unidades que correspondem às Delegacias da Mulher, haja vista que elas são consideradas, em estrutura e hierarquia, como uma Delegacia de Polícia de Comarca (DPCo). É importante ressaltar que, apesar de não constarem expressamente no organograma da instituição, existem delegacias especializadas na apuração de diferentes tipos de crimes. É o caso da Delegacia de Homicídios, Delegacia de Repressão a Roubos, Delegacia de Pessoas Desaparecidas, Delegacias de Crimes de Trânsito, Delegacia de Crimes Ambientais, Delegacia de Proteção ao Turista, uma Central de Operações Policiais Especiais, trinta Divisões de Investigação Criminal no Estado e as Delegacias de Proteção à Criança, Adolescente, Mulher e Idoso.

Para fins da presente análise, importa ressaltar as atribuições normativas das Delegacias Especializadas de Atendimento às Mulheres com a elaboração da Norma Técnica de Padronização das Delegacias Especializadas de Atendimento às Mulheres, analisada no item a seguir.

\section{Norma Técnica de Padronização das Delegacias Especializadas de Atendimento às Mulheres - DEAMs}

Por iniciativa da Secretaria Nacional de Segurança Pública, da Secretaria de Políticas para Mulheres e por diversos especialistas na atuação do Terceiro Setor, na área das relações de gênero e violências, foi elaborada no ano de 2006 (antes da promulgação da Lei Maria da Penha), a "Norma Técnica de Padronização das Delegacias Especializadas de Atendimento às Mulheres", com apoio do Ministério da Justiça e das Polícias Civis. Em conjunto com a elaboração do Plano Nacional de Políticas para Mulheres, da Política Nacional de Enfrentamento à Violência contra as Mulheres e do Pacto Nacional pelo Enfrentamento à Violência contra as Mulheres, houve a implementação de políticas públicas para as mulheres, tendo, nas DEAMs, o lócus de execução e articulação destas políticas.

Ao abordar o papel das Delegacias da Mulher, a diretriz ressalta as novas atribuições da Polícia Civil, em consonância com o Projeto de Modernização das Polícias Civis, elaborado pela Secretaria Nacional de Segurança Pública. Dentre essas atribuições, a Norma ressalta que compete à Polícia Civil desempenhar a primeira fase da repressão estatal, de caráter preliminar à persecução processual, e destaca que o papel da Polícia Civil não pode ser apenas como órgão repressor, "mas educador e aberto à audição do público usuário" (BRASIL, 2010, p. 28).

Segundo a Norma, os novos desafios para a Polícia Civil e para as Delegacias da Mulher consistem em agir com: a) profissionalização (posturas profissionalizadas por técnicas de gestão e ação operativa); b) prevenção (dissuasão, eficiência e eficácia do método investigativo e atuando como educadora da cidadania); c) educação e cidadania (correta audição do público usuário, superando o papel meramente reativo da atividade investigativa); d) investigação (executar de modo otimizado o ciclo produtivo do sistema de justiça criminal). (BRASIL, 2010, p.28)

Além de ressaltar os novos princípios de atuação das Delegacias, a norma técnica estabelece, expressamente, que as atividades das DEAMs "têm caráter preventivo e repressivo, devendo realizar ações de prevenção, apuração, investigação e enquadramento legal". (BRASIL, 2010 , p. 30). Além disso, desenvolvem ações complementares, tendo competências concorrentes com as delegacias de base territorial, devendo atuar com parceria, potencializando a ação policial na área territorial da respectiva especializada.

É importante mencionar que as DEAMs têm competência definida pela matéria, isto é, o tipo de crime a ser investigado: no caso, a violência de gênero. Assim, as beneficiárias diretas do serviço são todas as mulheres em situação de violências de gênero, e não somente aos crimes de violência doméstica e familiar nos termos da Lei Maria da Penha. Daí a importância do atendimento ser conduzido por profissionais previamente capacitados em violência de gênero.

O terceiro capítulo da Norma Técnica de Padronização descreve as novas atribuições das DEAMs em conformidade com a Lei Maria da Penha, no conjunto de uma política integral no 
enfrentamento das violências doméstica e familiar contra a mulher. Observa, de forma bastante acertada, que as novas atribuições são cumulativas, ou seja, somam-se às investigações originárias decorrentes da especialização de gênero:

Tendo em mente essas novas diretrizes e desafios, as ações de prevenção, registro de ocorrências, investigação e repressão de atos ou condutas baseadas no gênero, que configurem crime e infrações penais cometidos contra mulheres em situação de violência, devem ser feitas por meio de acolhimento com escuta ativa, realizada preferencialmente por delegadas, e por equipe de agentes policiais, profissionalmente qualificados e atentos ao fenômeno da violência de gênero, nos termos da Lei Maria da Penha. (BRASIL, 2010: p.29)

Sobre as medidas protetivas de urgência, é importante ressaltar que se trata de uma inovação importante no que se refere à proteção das vítimas de violência doméstica e familiar. Previstas no artigo 22 da Lei Maria da Penha, as medidas têm como objetivo proteger a ofendida e evitar a ocorrência de novos crimes ou de crimes mais graves. (BRASIL, 2006). Assim, pode ser requerido o afastamento do agressor do lar, a proibição de contato por qualquer meio, a proibição de aproximação a uma distância mínima, entre outras medidas. Elas podem ser solicitadas na Delegacia e devem ser encaminhadas pela autoridade policial ao Poder Judiciário no prazo de 48h para apreciação.

Apesar de prever condições ideais para estruturação das Delegacias da Mulher, é importante ressaltar que a referida Norma Técnica não é uma lei que obriga a Administração Pública, e sim uma diretriz nacional que visa melhorar os processos e padronizar as unidades no país. A implantação das diretrizes constantes nessa Norma é fundamental para a melhoria da qualidade de atendimento das vítimas e no fortalecimento do enfrentamento à violência doméstica e familiar contra a mulher.

Diante destas considerações, a próxima seção apresenta a análise dos dados obtidos junto a 19 Delegacias da Mulher em Santa Catarina, a respeito do perfil dos delegados e delegadas atuantes nessas DEAMs, seu conhecimento acerca das atribuições e procedimentos e as diretrizes preconizadas na Norma Técnica, e discute se há adequação às atividades policiais e às condições estruturais administrativas preconizadas pela Norma.

\section{Delegacias Especializadas de Atendimento à Mulher em Santa Catarina}

A história das delegacias da mulher em Santa Catarina começa com a criação da Delegacia da Mulher da Capital de Florianópolis em 1983, pelo Decreto estadual n.19.273, de 11 de abril de 1983; esta foi a segunda unidade especializada a ser criada no país, antecedida apenas pela Delegacia da Mulher de São Paulo, em 06 de agosto de 1985. Conforme Joacyr de Paula NIZER (2010, p. 142), foi por meio da Portaria 915/GAB/SSP/85, de 27 de setembro de 1985, que se designou o "setor de proteção à criança e adolescente e o setor de proteção à mulher", dentro do $6^{a}$ Distrito Policial. Desde então, a $6^{a}$ Delegacia de Polícia da Capital engloba a Delegacia da Criança e do Adolescente e a Delegacia da Mulher.

As razões para a criação dessa Delegacia podem ser encontradas no bojo das reivindicações dos movimentos feministas das décadas de 1970 e 1980 em Santa Catarina e das diversas ações de articulação política e mobilização de mulheres, como a realização dos Encontros Estaduais da Mulher Catarinense, que conferiram maior visibilidade ao tema das mulheres e das violências de gênero.

Após a criação da Delegacia da Mulher de Florianópolis, outras unidades foram criadas no Estado, atendendo esse mesmo público: mulheres, crianças e adolescentes, a partir da publicação, no Diário Oficial do Estado no dia 14 de janeiro de 2004, da Resolução 007/GAB/CPC/ SSP/2003, revogada pela Resolução n 008/GAB/DGPC/SSP/2013, de 07 de outubro de 2013.

De acordo com a mencionada resolução, as Delegacias passam a ser chamadas "da Mulher, da Criança e do Adolescente" e não apenas "Delegacia da Mulher", possuindo atribuições relacionadas à proteção das crianças, à apuração de atos infracionais cometidos por adolescentes, além da apuração de ilícitos criminais contra a mulher.

É importante notar que essa portaria não diferencia os crimes cometidos contra mulheres, entre violência doméstica e crimes comuns. O que orienta a atribuição da delegacia é o sexo sujeito passivo: se for mulher, vítima de qualquer violência física ou moral praticada por homem, deve ser atendida na unidade. Da mesma forma, qualquer ato de violência sexual perpetrado contra a mulher, independente do sexo do agressor, a atribuição é também da especializada. Vale frisar: a circunscrição, ou seja, o âmbito de atuação da delegacia, corresponde à comarca onde ela está situada. Desta forma, a $6^{a}$ Delegacia da Capital, por exemplo, atende todas as mulheres de Florianópolis que sofrerem os crimes acima descritos, além de todas as crianças vítimas e os adolescentes em conflito com a lei.

Após a criação da Delegacia da Mulher de Florianópolis, sob a forma de setor especializado dentro da $6^{a}$ Delegacia da Capital, as demais unidades foram criadas sucessivamente por lei, 
subordinando-se às Delegacias Regionais de Polícia (DRP), num total de 30 Delegacias da Mulher no Estado. Registra-se, também, a criação da Coordenadoria das DEAMs no atendimento à mulher, criança, adolescente e idoso no Estado de Santa Catarina no ano de 2015, com uma gestora à frente dessa Coordenadoria, conforme prevê a Norma Técnica.

A pesquisa analisada neste artigo foi realizada com 19 Delegacias da Mulher em Santa Catarina. Após contatos via e-mail e telefônicos com todos/as delegados e delegadas atuantes nas 30 Delegacias regionais do Estado, 19 consentiram em participar da pesquisa com o devido preenchimento do Termo de Consentimento Livre e Esclarecido (TCLE), reenviado por e-mail para as pesquisadoras. Após o recebimento do TCLE, o questionário foi elaborado pelas pesquisadoras e enviado por e-mail, em formato de formulário online, para os participantes, com o prazo de 20 dias para a devolução. As 19 DEAMs participantes da pesquisa pertencem às seguintes regiões: Porto União, Mafra, São Joaquim, Itajaí, Araranguá, Joinville, Blumenau, Palhoça, Tubarão, Campos Novos, Rio do Sul, Lages, Chapecó, Jaraguá do Sul, Balneário Camboriú, Joaçaba, Florianópolis, Videira e São Bento do Sul.

As perguntas fechadas referem-se à autodenominação dos respondentes em relação ao gênero, tempo de serviço na DEAMs, faixa etária, se realizou cursos de formação em gênero e se eram representantes de algum conselho municipal, estadual ou federal. Um outro grupo de questões quantitativas referia-se à estrutura física das DEAMs, seus equipamentos, rotina/horário de funcionamento, às atribuições e procedimentos realizados ou implantados pela Especializada, as diretrizes preconizadas na Norma e os crimes investigados pelas DEAMs.

O perfil descrito revelou que a maioria dos delegados e delegadas se autodenomina pertencente ao sexo masculino ( 13 delegados e 6 delegadas) e possui pouco tempo de serviço (5 anos) na Especializada. A faixa etária predominante é de 30-40 anos, seguida pelos que possuem entre 40-50, dois delegados com idade inferior a 30 anos e dois na faixa etária de 50-60 anos.

Este perfil de homens relativamente jovens, com pouco tempo de serviço nas Especializadas, também se repete em outras regiões de Santa Catarina, como aponta a pesquisa de Maria Aparecida Casagrande (2017). A autora mostra que, no ano de 2016 , havia $33 \%$ de mulheres na Polícia Civil catarinense, no âmbito do quadro efetivo geral, ou seja, de 3.421 policiais, 1.129 eram mulheres. Por sua vez, destas 1.129 mulheres, havia 712 agentes de polícia, 73 delegadas, 284 escrivãs e 60 psicólogas. (CASAGRANDE, 2017, p. 4)

Em proporção aos homens - 1.654 agentes de polícia, 338 delegados, 281 escrivães e 19 psicólogos - as mulheres superam significativamente os homens apenas nos cargos de psicólogo, o que nos leva a pensar na naturalização dos papeis de gênero relativos ao cuidado e ao suporte emocional como atributos das mulheres e não dos homens. Da mesma maneira, se os homens são maioria expressiva nas atividades de agentes policiais e delegados, entende-se que há um reforço na naturalização dos papeis masculinos associados à segurança, proteção e às relações de poder e força no desempenho de suas atividades no espaço público.

A pesquisa de Wânia Pasinato e Cecília MacDowell Santos (2008) já demonstrava esse perfil masculino, com $83,4 \%$ de homens delegados contra $16,6 \%$ de mulheres delegadas no ano de 2008, com pouca variação entre os Estados da Federação.

\begin{abstract}
A presença feminina é menor em estados nos quais a carreira é mais antiga (como São Paulo, onde há apenas $10 \%$ de mulheres); é maior naqueles estados onde a carreira é mais recente, menos estruturada e, consequentemente, com remuneração mais baixa, como, por exemplo, na Bahia, onde $47,4 \%$ do efetivo de delegados concursados são mulheres. Uma pesquisa nacional realizada pela SENASP2 mostrou que, em 2004, existiam no país 69.156 profissionais (policiais e não policiais) na polícia. As mulheres correspondiam a $22 \%$ dos membros da corporação. A distribuição por sexo entre as funções é bastante desigual: nas chamadas funções operacionais (delegados, investigadores de polícia), há em média 4,6 homens para cada mulher; naquelas de apoio administrativo (como escrivão de polícia), há 0,8 homens para cada mulher. A mesma pesquisa mostra que a idade de $42,8 \%$ dos funcionários variava entre 35 e 45 anos e $33,4 \%$ estavam acima dessa faixa, o que reflete uma predominância de jovens na corporação. (PASINATO; SANTOS, 2008: p. 22)
\end{abstract}

Quanto aos cursos de formação, verificamos que apenas oito delegados possuem cursos sobre gênero ou Lei Maria da Penha, o que demonstra duas situações: não há preparação especializada nas questões de gênero por parte dos delegados e delegadas, agravados com o pouco tempo de serviço na Especializada, e a necessidade de investimento em formação continuada que qualifique adequadamente esses profissionais em relação à temática de gênero e violências. Não se pode esquecer que a qualidade do atendimento e a atenção integral das vítimas têm relação direta com o conhecimento sobre a legislação e os deveres inerentes à Polícia Civil no enfrentamento à violência de gênero.

A qualidade deste atendimento também está diretamente relacionada ao grau de interlocução com outros órgãos, o que se revelou muito baixo, de acordo com os respondentes da

2 SENASP - Secretaria Nacional de Segurança Pública 
pesquisa. Apenas seis delegados participam como representantes das DEAMs em algum conselho Federal, Estadual ou Municipal, o que demonstra uma baixa capilaridade e adesividade entre as redes de atuação/prevenção e as DEAMs.

Importa ressaltar que os/as delegados e delegadas sabiam da existência da Norma Técnica das DEAMS, o que se confirmou nas respostas relacionadas às atribuições e procedimentos realizados e condições estruturais administrativas das DEAMs, na segunda parte do questionário.

Entendem como principal atribuição das DEAMs o atendimento à mulher em situação de violência, porém, nem todas as delegacias cumprem fielmente o disposto na Resolução 007/GAB/ 2003. Dos 19 delegados respondentes, 15 dizem seguir literalmente o que está previsto na primeira parte da resolução: "Apurar os ilícitos criminais referentes à prática de violência física e moral contra a mulher, cujo sujeito ativo do delito seja pessoa do sexo masculino", enquanto 14 disseram cumprir a atribuição prevista na segunda parte da referida resolução: "Apurar os ilícitos criminais referentes à prática de violência sexual contra a mulher, cujos sujeitos ativos sejam pessoas do sexo masculino e feminino". (POLICIA CIVIL DO ESTADO DE SANTA CATARINA, 2013).

Essas divergências relacionadas às atribuições são enfrentadas diariamente pelas DEAMs pois as demais unidades policiais tendem a encaminhar toda a vítima mulher, criança, adolescente e idoso às especializadas, restando às Delegacias comuns a atribuição exclusiva para atender os crimes praticados contra outras vítimas.

Quanto aos crimes investigados pela Delegacia Especializada ${ }^{3}$, a única resposta assinalada referente às atribuições refere-se à apuração de atos infracionais praticados por adolescentes. Ou seja, o único padrão de atendimento nessas delegacias é que todas são responsáveis pelos adolescentes em conflito com a lei.

Há, ainda, o registro de seis Delegacias que dizem atender todo o tipo de crime cometido contra a mulher, em sua área de circunscrição, desde que tenham sido cometidos por homens. Desta forma, nessas unidades, ainda que não se enquadre no conceito da Resolução 007/GAB/ 2003, tampouco na Lei Maria da Penha, mesmo assim o crime é apurado pela Delegacia da Mulher.

O artigo 12 da Lei Maria da Penha determina à Autoridade Policial procedimentos diferenciados para o atendimento da ofendida, descrevendo a necessidade de "tomar a termo a representação, se apresentada". (BRASIL, 2006). Nos crimes de Ação Penal Pública Condicionada, no qual a representação é necessária, essa informação deve ser prestada à vítima, assim como sobre a impossibilidade de renúncia na Delegacia. Sobre esse item, 94,73\% das Delegacias responderam que prestam orientação acerca da necessidade de representação ou queixa-crime, nos casos em que os crimes se processam mediante Ação Penal Pública condicionada e Ação Penal Privada.

Com relação ao pedido de concessão de Medidas Protetivas de Urgência, previsto no artigo 12, inciso III, da Lei 11.340/06, todas as Delegacias responderam que confeccionam e encaminham ao juízo competente. Esse pode ser o fator que diferencia o atendimento em uma Delegacia de Polícia, já que é o único órgão estadual que realiza tal serviço de forma pública e gratuita (pelo menos enquanto não se implanta a Defensoria Pública no Estado). Além disso, em caso de descumprimento por parte do agressor, $89,47 \%$ dos delegados responderam que têm representado pela Prisão Preventiva e $94,73 \%$ têm realizado operações externas para cumprimento dos mandados de prisão e condução coercitiva. Na questão relativa à apuração de Violência Doméstica e Familiar contra a mulher, 18 Delegacias responderam que apuram todas as formas dessa espécie de violência.

Além do volume de trabalho gerado pela demanda que recai sobre as especializadas, tem-se a necessidade de adotar procedimentos especiais de atendimento às vítimas, especialmente em razão da previsão contida no artigo 11 da Lei Maria da Penha. Desta forma, inserimos no questionário aos delegados uma questão sobre quais destes procedimentos são adotados pelas Delegacias, chegando-se aos seguintes resultados:

Tabela 1 - Percentual de Delegacias que realizam as atribuições

\begin{tabular}{|c|c|}
\hline Previalo legal & Delegacias que realizam (\%) \\
\hline 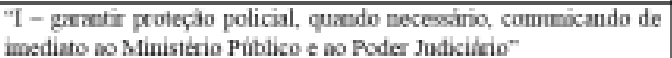 & $52,65 \%$ \\
\hline 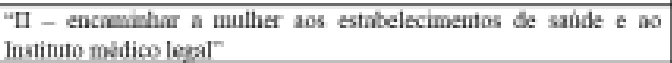 & $84.21 \%$ \\
\hline $\begin{array}{l}\text { "ПII - focoecer transpocte pees a ofondida e seus dependentes pora } \\
\text { abrigo seguro, quando bouver risco de vida" }\end{array}$ & $63.15 \%$ \\
\hline $\begin{array}{l}\text { "IV - acompanbaj-h para retirada de seus periences, quando } \\
\text { necesefrio" }\end{array}$ & $94,75 \%$ \\
\hline "V - informi-1a de seas direitos e sobre cos servicos dispoenveis" & $100 \%$ \\
\hline
\end{tabular}

Fonte: Questionários aplicados

${ }^{3}$ Com relação aos crimes praticados contra as mulheres, há que se observar a distinção que a Norma faz entre dois tipos de ocorrência: os crimes comuns, que vitimam tanto as mulheres como os homens (ex: furto, roubo, estelionato, ameaça, lesão corporal), e aqueles nos quais a mulher é vítima de violência doméstica e familiar (todo o crime cometido nos termos da Lei Maria da Penha) em consonância com o artigo $7^{\circ}$ da Lei Maria da Penha. 
Verifica-se, desta forma, que o atendimento às vítimas nas unidades pesquisadas ainda não é integral, conforme prevê a Lei Maria da Penha. Vários fatores podem contribuir para que as atribuições acima elencadas não sejam efetivamente realizadas pelas Delegacias: 1) Desconhecimento por parte das vítimas, que deixam de solicitar os serviços; 2) Desconhecimento por parte dos policiais de que é dever da Polícia realizar tais tarefas; 3) Dificuldades operacionais, em razão de baixo número de policiais no plantão ou de escassez de viaturas para a demanda; 4) Acordo com outras entidades como Conselho Tutelar, Centros de Referência, Polícia Militar e Guarda Municipal, as quais prestam o serviço de forma auxiliar, desobrigando a Delegacia.

Em razão da peculiaridade da Polícia Civil catarinense, que possui em seu quadro funcional o Psicólogo Policial, $78,94 \%$ das Delegacias realizam atendimento psicológico às vítimas atendidas na unidade. Essa atividade pode contribuir para o acolhimento das vítimas, especialmente por oferecer uma escuta qualificada e uma orientação técnica especializada. Entretanto, é importante observar que não é realizado qualquer tipo de tratamento ou terapia na Delegacia, embora possa haver encaminhamento aos órgãos da rede de atendimento.

Ressalta-se que $63,15 \%$ das unidades policiais especializadas afirmaram seguir protocolo de atendimento padronizado para as vítimas de violência sexual, em parceria com outros órgãos da rede de atendimento. Em Florianópolis, esse protocolo se chama "Protocolo de Atenção às Vítimas de Violência Sexual do Município de Florianópolis", e foi firmado entre a Prefeitura Municipal, a Secretaria de Segurança Pública, a Universidade Federal de Santa Catarina, a Secretaria de Justiça e Cidadania e a Secretaria de Saúde.

Por este protocolo, a vítima de violência sexual poderá dar entrada em qualquer instituição pública ou privada das áreas da saúde, segurança, órgãos de proteção à infância ou de cunho social, devendo ser encaminhada imediatamente às Unidades de Referência da Rede de Atendimento: Universidade Federal de Santa Catarina, Maternidade Carmela Dutra e Hospital Infantil Joana de Gusmão.

Nessas unidades, o atendimento é realizado de acordo com um fluxograma que considera a idade da vítima e o tipo de crime sexual praticado: a $6^{a}$ Delegacia é acionada nos casos em que há violência sexual contra crianças e adolescentes, e comparece ao local para registro compulsório do Boletim de Ocorrência, providenciando o acionamento do IML, que também comparece ao local para exame de corpo de delito; caso a vítima seja maior de 18 anos, a Delegacia somente é acionada se houver interesse da mesma vítima. De qualquer forma, são coletados os materiais necessários para futuros exames e encaminhados ao IML, caso a vítima decida requisitar a investigação posteriormente. Desta forma, a mesma não precisa sair do hospital e procurar outras unidades como uma delegacia ou IML, o que contribui para reduzir os danos e traumas provocados pelo crime. A vítima é, ainda, encaminhada para atendimento psicossocial e jurídico junto ao CEAV (Centro de Atendimento às Vítimas de Crimes).

Em algumas localidades não há um protocolo a ser seguido, motivo pelo qual as próprias Delegacias criaram rotinas internas para melhoria do atendimento. É o caso de $43,1 \%$ das delegacias que responderam ao questionário desta pesquisa.

Além de todas essas atividades relacionadas diretamente ao atendimento de mulheres, os delegados responderam que realizam operações externas de fiscalização em bares, boates e casas noturnas (58\%), além de mutirões para conclusão de procedimentos em atraso $(36,84 \%$ ) e reuniões de trabalho e avaliação de desempenho dos servidores da unidade $(47,36 \%)$.

Outra questão relacionada aos procedimentos efetuados na Especializada diz respeito à utilização do Sistema Integrado de Segurança Pública - SISP. Esse sistema possui integração de diversos bancos de dados, sendo utilizado e alimentado por órgãos da Segurança Pública e do Poder Judiciário, constituindo-se importante ferramenta de investigação e execução do trabalho policial. Desta forma, é importante que as Delegacias utilizem as rotinas do SISP para alimentar o banco de dados e proporcionar estatísticas criminais confiáveis, especialmente no tocante à violência de gênero. Neste aspecto, verificamos que 100\% das Delegacias que responderam ao questionário utilizam o Sistema Integrado de Segurança Pública para confecção de Boletins de Ocorrência, Termos Circunstanciados e Inquéritos Policiais. Quanto aos Autos de Prisão em Flagrante, apenas uma delegacia respondeu não realizá-lo no ambiente do SISP.

Em relação à estrutura administrativa, a falta de padronização já começa pela nomenclatura: grande parte se denomina "DPCAMI (Delegacia de Proteção à Criança, Adolescente, Mulher e Idoso", enquanto algumas se dizem "DPCAMI-FRON (Delegacia de Proteção à Criança, Adolescente, Mulher e Idoso de Fronteira) ", e uma se chama "6a Delegacia de Polícia da Capital". Entretanto, nenhuma das nomenclaturas existe por lei, conforme se verifica a partir dos Decretos estaduais de criação. Cada Decreto criou uma unidade e a batizou com nome distinto; em algumas regionais, a denominação oficial é "Delegacia de Proteção à Mulher", enquanto em outras é "Delegacia de Proteção à Mulher, Criança e Adolescente". Administrativamente, para garantir uma padronização mínima, no ano de 2008 passou a se instituir a denominação extraoficial "DPCAMI - Delegacia de Proteção à Criança, Adolescente, Mulher e Idoso" para todas as unidades 4 . 
Já com relação à denominação "DPCAMI - Fron", origina-se do Projeto ENAFRON - Estratégia Nacional de Segurança Pública nas Fronteiras, um convênio celebrado entre Estado e Federação, por meio do Ministério da Justiça e Secretaria Nacional de Segurança Pública. De acordo com o Decreto estadual n.1.227, de 30 de outubro de 2012, as unidades policiais localizadas em regiões de fronteira passam a receber nova denominação. Assim, por exemplo, a região de Chapecó passa a ser a $12^{a}$ Delegacia Regional de Polícia de Fronteira - $12^{a}$ DRP-Fron, e assim as unidades policiais subordinadas, motivo pelo qual a DPCAMI de Chapecó se denomina DPCAMI - Fron. (SANTA CATARINA, 2012)

A denominação interfere nas rotinas de atendimentos, "delegacias especiais de defesa da mulher", ou "delegacias de proteção à mulher" diferem de "delegacias de atendimento" à mulher, pois refletem nas práticas policiais e nas expectativas da demanda. Neste sentido, visando padronizar o atendimento, o artigo $8^{\circ}$, inciso IV, da Lei Maria da Penha define como uma das diretrizes de política pública "a implementação de atendimento policial especializado para as mulheres, em particular nas Delegacias de Atendimento à Mulher". Assim, para esta lei, as unidades policiais devem ser denominadas DEAMs - Delegacias de Atendimento à Mulher e possuir atendimento policial especializado.

As áreas de atuação também não seguem um padrão: algumas delegacias têm o âmbito circunscricional adstrito à cidade sede da Comarca onde estão instaladas (Ex: Porto União, Joaçaba, Palhoça, Joinville, Florianópolis, Itajaí), enquanto outras atendem ao público das cidades vizinhas (Ex: Rio do Sul, que atende Agronômica, Lontras, Presidente Nereu e Aurora; São Bento do Sul que atende também Campo Alegre; Campos Novos que atende também Zortéa, Brunópolis e Vargem; Jaraguá do Sul, que atende também Corupá).

Com relação aos equipamentos disponíveis, é importante ressaltar que todas possuem computadores com acesso à internet e a maioria conta com impressoras a laser, o que confere qualidade na produção dos documentos. Além disso, $84 \%$ das delegacias responderam que possuem ar condicionado nas salas de atendimento, o que contribui para aumentar a qualidade do ambiente e do serviço, conforme tabela 2:

Tabela 2 - Equipamentos disponíveis nas Delegacias pesquisadas

\begin{tabular}{l|l} 
Equipamentos & $\mathrm{N}^{\circ}$ de Delegacias \\
\hline Computadores com acesso à internet & 19 \\
\hline Ar condicionado nas salas de atendimento & 17 \\
\hline Notebook & 10 \\
\hline Modem 3G & 0 \\
\hline Impressoras laser & 14 \\
\hline Televisor & 9 \\
\hline Máquina fotográfica digital & 18 \\
\hline Webcam para computadores & 9 \\
\hline Filmadora digital & 3 \\
\hline Gravadores portáteis de voz & 1 \\
\hline Central de rádio & 1 \\
\hline Rádios HT & 1 \\
\hline Viaturas com cela & 7 \\
\hline Viaturas descaracterizadas & 13
\end{tabular}

Fonte: Questionários aplicados

Com relação ao armamento policial, 14 unidades responderam que todos os policiais possuem arma sob cautela. Apenas 5 unidades responderam que "a maioria" de seus policiais têm armas. Diferente do que ocorre em outras corporações, na Polícia Civil catarinense o policial recebe a arma no momento em que se forma na Academia de Polícia, após passar pelo treinamento recomendado pela matriz curricular da SENASP, apontado no gráfico 1:

\footnotetext{
${ }^{4} \mathrm{~A}$ inserção da população idosa no atendimento preferencial por esta especializada se deu exclusivamente em razão da publicação do Estatuto do Idoso (Lei 10.741, de $1^{\circ}$ de outubro de 2003). Não há criação formal dessas unidades no Estado, tampouco existe Portaria regulamentadora das atribuições que essas delegacias possuem. O fato é que tal demanda subdividiu ainda mais os trabalhos da Delegacia da Mulher, a qual já contava com setor de proteção à criança e ao adolescente, além do atendimento de adolescentes em conflito com a lei. A Delegacia da Mulher da Capital foi a única unidade especializada que não incorporou a demanda do idoso, realizando atendimentos apenas a Crianças, Adolescentes e Mulheres.
} 
Gráfico 1 - Policiais que possuem armamento sob cautela

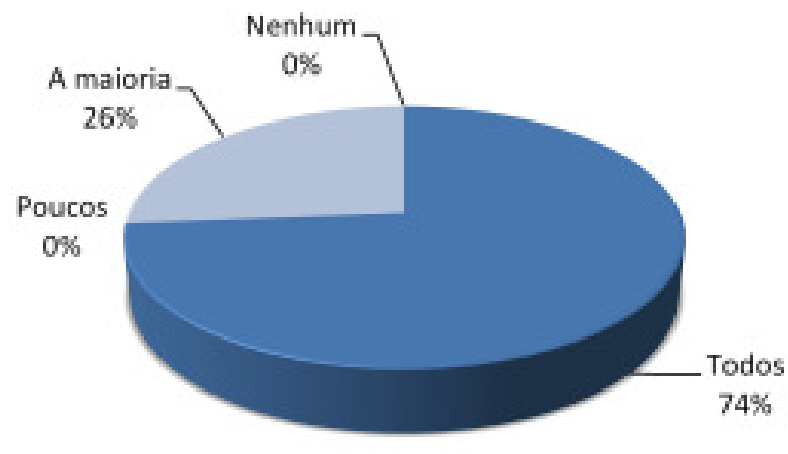

Fonte: Questionários aplicados

Quanto às algemas e coletes balísticos, uma Delegacia respondeu que nenhum de seus policiais possui algema e colete balístico, $26 \%$ afirmou usar ambos os equipamentos, quando 0 ideal é que todos os policiais recebam esses itens no momento de sua formação na Academia, como ocorre com o armamento de uso pessoal.

Da mesma forma, o gráfico 2 mostra o uso dos telefones funcionais, cuja conta é custeada pelo Estado até certo limite e garante gratuidade de comunicação entre telefones da mesma operadora; são poucos os policiais que possuem. Apenas três Delegacias responderam que este telefone foi concedido à maioria dos policiais.

Gráfico 2 - Policiais que possuem telefones funcionais

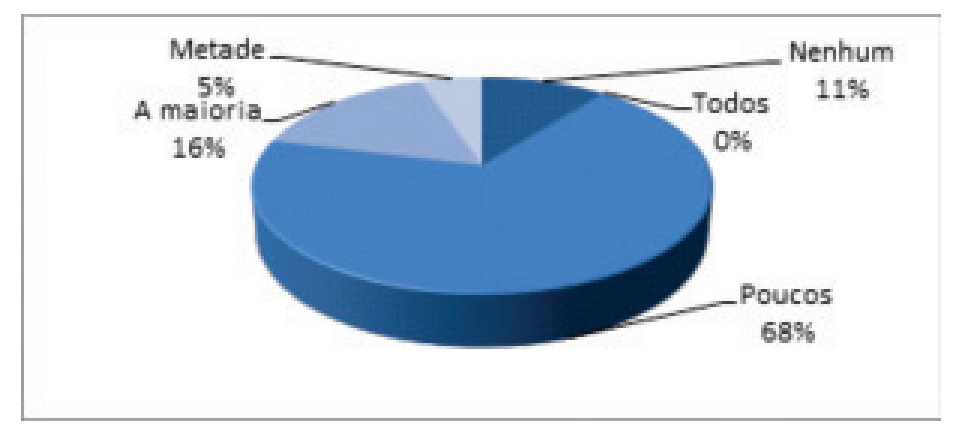

Fonte: Questionários aplicados

Quanto ao horário de atendimento, $47 \%$ atendem somente em horário de expediente (compreendido entre $8 \mathrm{~h}-18 \mathrm{~h}$ ), enquanto $16 \%$ realizam sobreaviso noturno e $37 \%$ atendem em regime de plantão 24 horas. Em outras regiões do Brasil, como no Centro Oeste e Sudeste, a pesquisa coordenada por Pasinato (2013) constata que os atendimentos estão circunscritos aos horários de expediente e aos dias da semana:

Nas oito delegacias visitadas na região, apenas as $1^{a}$ DEAM de Goiânia e a DEAM de Brasília funcionam 24 horas, inclusive nos finais de semana. Em Goiânia, durante o plantão também registram ocorrências de crimes contra crianças e adolescentes. Nas outras cidades as DEAMs funcionam em horário de expediente ( 8 horas diárias de $2^{a}$ a $6^{a}$ feira). Fora desse horário 0 atendimento é realizado nos plantões ou nas centrais de flagrante. (PASINATO, 2013: p.16)

Quanto à estrutura, o questionário apresentou opções referentes à infraestrutura existente no espaço das unidades respondentes da pesquisa, conforme apresenta a tabela 3.

Os espaços deveriam ser divididos entre área de recepção, de registro, de assistência judiciária, para a equipe técnica, para coordenação, áreas de apoio e áreas comuns. É importante ressaltar que, quanto à área para recepção, apenas duas delegacias possuem espaços separados para agressor e vítima e somente uma possui vestiários separados para homens e mulheres. A designação destes espaços separados é condição essencial para a não reprodução de formas de violência já no ato da recepção e no interior dos espaços da própria Delegacia.

Mas não é essa a realidade nas outras Delegacias, nas quais as mulheres são obrigadas a dividir o mesmo espaço com seus agressores ou com as demais pessoas que estão nas delegacias 
e plantões policiais, prestando outras queixas ou realizando outras atividades, o que compromete o necessário acolhimento e a atenção dispensada à mulher em situação de violência.

Tabela 3 - Estrutura da Delegacia

\begin{tabular}{|c|c|}
\hline Quanto à estrutura da Delegacia, assinale o que a unidade possui: & $\mathrm{N}^{\circ}$ de Delegacias \\
\hline recepção com espaços separados para agressor e vítima & 2 \\
\hline $\begin{array}{l}\text { comissariado com salas ou repartições privativas (individualizadas) para registro } \\
\text { do boletim de ocorrência }\end{array}$ & 11 \\
\hline $\begin{array}{l}\text { comissariado sem salas ou repartições privativas (individualizadas) para registro } \\
\text { do boletim de ocorrência }\end{array}$ & 5 \\
\hline $\begin{array}{l}\text { cartório (s) policial (is) reservados, onde o depoimento é prestado com sigilo, } \\
\text { garantindo separação entre vitima e agressor }\end{array}$ & 16 \\
\hline sala para advogados ou assistência judiciária & 0 \\
\hline sala (s) para atendimento psicológico & 15 \\
\hline sala da investigação & 4 \\
\hline sala com espelho gessel (para reconhecimento) & 4 \\
\hline sala para a coordenação (Delegado de Polícia) & 18 \\
\hline sala de espera para atendimento com o Delegado de Polícia & 9 \\
\hline sala de reunião & 1 \\
\hline Almoxarifado & 3 \\
\hline Arquivo & 13 \\
\hline sala de equipamentos e armas & 2 \\
\hline sala de estar/espaço de convivência para os servidores & 0 \\
\hline copa-cozinha & 12 \\
\hline sala de detenção provisória & 2 \\
\hline cela para permanência de presos & 8 \\
\hline estacionamento para policiais & 12 \\
\hline estacionamento para viaturas & 15 \\
\hline estacionamento para público em geral & 2 \\
\hline sala para crianças - brinquedoteca & 4 \\
\hline sala para atendimento de crianças vítimas de violência, com recursos de apoio & 5 \\
\hline sala de protocolo de documentos & 7 \\
\hline banheiros separados - feminino e masculino & 9 \\
\hline vestiários separados - masculino e feminino & 1 \\
\hline vestiário de uso comum & 2 \\
\hline alojamento para policiais - separado masculino e feminino & 2 \\
\hline alojamento para policiais - de uso comum & 7 \\
\hline sala para exames médicos & 0 \\
\hline Acessibilidade a portadores de necessidades especiais & 6 \\
\hline
\end{tabular}

Fonte: Questionários aplicados

Por outro lado, $58 \%$ das unidades responderam possuir comissariado com salas ou repartições individualizadas para registro do boletim de ocorrência e 84,21\% possuem cartórios policiais reservados, onde o depoimento é prestado com sigilo, garantindo separação entre vítima e agressor. Também é significativo ressaltar a ausência de salas para advogados, salas de estar para convivência entre os servidores e salas para exames médicos.

Pasinato (2013) constata em sua pesquisa que, apesar das DEAMs das regiões do Centro Oeste e Sudeste afirmarem a prioridade na atenção diferenciada para as mulheres no ato do registro "em relação ao restante do movimento de pessoas e documentos que circulam pelas delegacias e plantões policiais", essa atenção ainda está bastante distante das diretrizes preconizadas nas Normas Técnicas, conforme se pode observar em seu relato:

Em todas as delegacias se encontram apenas uma sala de espera comum. Ali estão dispostas algumas cadeiras, às vezes mesas com brinquedos para as crianças, o balcão de atendimento e um aparelho de televisão permanentemente ligado, mas nunca exibindo conteúdo educativo. 
Para as delegadas, a inexistência de espaços separados para vítimas e agressores (como recomendado na Norma Técnica) não representa um problema, pois afirmam que a mulher nunca permanece na sala com seu próprio agressor. Se for um flagrante, ele é levado para outra sala (pode ser a sala de detenção provisória, ou locais improvisados com barras de ferro onde possa ser mantido algemado). Se o agressor comparece por intimação, isso não ocorre com a presença da vítima no local. De qualquer forma parece importante observar que a mulher pode ficar ali na presença de agressores de outras mulheres, o que também pode ser considerado um constrangimento para quem já se encontra fragilizada e insegura com as decisões que está tomando. (PASINATO, 2013: p.21)

Essa situação é muito grave e representa uma violação do direito ao acolhimento humanizado e a privacidade do depoimento da mulher, previstos na Norma, o que compromete significativamente a escuta ativa e qualificada por parte da autoridade policial. Tanto a concepção arquitetônica das Delegacias quanto a postura dos agentes policiais devem propiciar um atendimento acolhedor que respeite as seguintes diretrizes da Norma:

\begin{abstract}
- a existência de ambientes separados para a vítima e o agressor; - o acolhimento humanizado, garantindo a privacidade do depoimento da mulher; - a ausência de preconceitos ou discriminações no atendimento; - a equipe de atendimento ser qualificada profissionalmente, no tema de gênero e, de preferência, do sexo feminino; - o conhecimento das diretrizes e procedimentos, além da disponibilidade de materiais de informação e orientação para as mulheres; - o acolhimento de todas as mulheres em situação de violência de gênero. (BRASIL, 2010: p.36).
\end{abstract}

Com relação à área para equipe técnica, ressalta-se que 15 unidades possuem sala específica para atendimento psicológico. Por outro lado, a sala para a investigação e a sala para reconhecimentos, com espelho gessell ${ }^{5}$, estão presentes em apenas quatro unidades policiais.

Outro ponto importante que o questionário revelou diz respeito à acessibilidade do público externo: o estacionamento para público em geral somente é presente em duas unidades policiais e apenas seis Delegacias responderam estar adequadas ao acesso por portadores de necessidades especiais. Esse fato ocorre porque muitas unidades policiais são instaladas em espaços locados, os quais não foram construídos com a finalidade específica de abrigar uma especializada. O Estado, entretanto, deverá providenciar as reformas e ampliações necessárias para garantir o amplo acesso da população, conforme a exigência legal.

Apenas nove delegacias relataram possuir alojamento para os policiais, sendo que em sete unidades ele é de uso comum para homens e mulheres. Também na maioria das unidades não existe a separação de banheiros entre os públicos feminino e masculino. Além disso, nenhuma delegacia respondeu possuir sala de estar/espaço de convivência para os servidores. Esses dados podem expressar o quanto o espaço policial ainda é eminentemente masculino e autoritário, com pouca abertura à prática acolhedora, tanto para o público externo, como para os novos e novas policiais que possam integrar a equipe.

Percebe-se, portanto, uma inadequação tanto dos procedimentos quanto das condições estruturais administrativas das unidades respondentes, ao ideal previsto nas diretrizes da Norma Técnica de Padronização das Delegacias Especializadas de Atendimento às Mulheres.

\title{
Considerações finais
}

Apesar da Polícia Civil catarinense ser pioneira na inauguração da Delegacia de Proteção à Mulher no Estado de Santa Catarina, há muito o que adequar em termos de organização administrativa, regulamentação de atribuições e estruturação das unidades perante a Norma Técnica. A análise mostrou que as DEAMs pesquisadas estão em condições estruturais muito frágeis e que isso acarreta um precário atendimento às mulheres em situação de violência.

As delegacias são majoritariamente comandadas por delegados homens, com pouco tempo de serviço na Especializada, o que já contraria o previsto na Norma em relação à equipe ser preferencialmente do sexo feminino. Também revelou fragilidades quanto aos cursos de formação nas questões de gênero por parte dos delegados e delegadas e à baixa interlocução com outros órgãos da rede de atendimento.

Estas fragilidades também são observadas nas atividades executadas nas referidas Delegacias, tanto em relação às atribuições e procedimentos quanto aos serviços oferecidos às mulheres. A falta de um padrão para as unidades especializadas é visível desde a nomenclatura atribuída a cada uma: o nome que consta nas placas das Delegacias (DPCAMI) não corresponde à nomenclatura atribuída pelas leis de criação. O mesmo se pode afirmar quanto à estrutura física

\footnotetext{
${ }^{5}$ Espelho gessell é um vidro com espelhamento unidirecional, ou seja, uma janela de vidro peliculada que permite a observação das pessoas que estão no outro lado do espelho. As pessoas observadas, entretanto, não conseguem ver seus observadores, motivo pelo qual este tipo de espelhamento é utilizado em salas de reconhecimento de autores de crimes.
} 
e aos equipamentos à disposição de tais unidades, o que compromete seriamente a garantia de um serviço de qualidade que integralize a atenção e proteção da mulher em situação de violência que procura a Delegacia.

Somente a partir da reformulação das atribuições na normativa interna e da estruturação das unidades com os equipamentos e recursos humanos necessários é que se poderá falar em efetiva implementação das diretrizes da Política Nacional de Enfrentamento à Violência contra as Mulheres pelo respeito e adequação à Norma Técnica.

A Delegacia precisa ser um espaço de acolhimento e proteção, funções estas que exigem uma postura diferenciada por parte da Polícia Civil, superando a lógica repressiva-punitiva. A qualidade do serviço passa, antes, pela reformulação dos conceitos de "ação policial", por parte da própria instituição, e também dos policiais que trabalham nas unidades especializadas.

\section{Referências bibliográficas}

ALVAREZ, Sonia E. "Para além da sociedade civil: reflexões sobre o campo feminista. " Cadernos Pagu, Campinas, n.43, p.13-56, jan/jun.2014.

AMORIM, João Schorne de. Sistema Nacional de Segurança Pública. Palhoça: Unisul Virtual, 2009.

BRASIL. Constituição da República Federativa do Brasil. Promulgada em 5 de outubro de 1988. Disponível em: http://www.planalto.gov.br/ccivil_03/constituicao/constituicao.htm. Acesso em 10/ 03/2018.

BRASIL. Lei n. 11.340, de 7 de agosto de 2006. Cria mecanismos para coibir a violência doméstica e familiar contra a mulher. Disponível em: http://www.planalto.gov.br/ccivil_03/_ato2004-2006/2006/ lei/l11340.htm. Acesso em10/03/2018.

BRASIL. Norma Técnica de Padronização das Delegacias Especializadas de Atendimento às Mulheres. Secretaria de Políticas para as Mulheres. Brasília, 2010. Disponível em: http:// www.spm.gov.br/lei-maria-da-penha/lei-maria-da-penha/norma-tecnica-de-padronizacao-dasdeams-.pdf. Acesso em 10/03/2018.

CASAGRANDE, Maria Aparecida. Ser mulher na polícia civil: um estudo sobre as delegadas de polícia em formação na Acadepol/SC em 2016. In: SEMINÁRIO INTERNACIONAL FAZENDO GÊNERO 11 \& 13 MUNDO DE MULHERES, 2017, Florianópolis, UFSC. Anais do Seminário internacional Fazendo Gênero 11 \& 13. Mundos de Mulheres. Florianópolis: UFSC, 2017. p.1-12.

PREFEITURA MUNICIPAL DE FLORIANÓPOLIS. Secretaria Municipal de Saúde. Programa Saúde da Mulher. Protocolo de Atenção às Vítimas de Violência Sexual do Município de Florianópolis. Tubarão: Editora Copiart, 2010. Disponível em: http://www.pmf.sc.gov.br/arquivos/arquivos/pdf/ 05_08_2011_9.35.51.3a63f3314c0be02ad278320128d3574a.pdf. Acesso em10/03/2018.

NIZER, Joacyr de Paula. "Agressões contra mulheres em Florianópolis, segundo os boletins de ocorrência registrados nas Delegacias da Capital em 2006." In: CÓRDOVA, Luiz Fernando Neves. et.al. (Org.). Os 25 anos da "Delegacia da Mulher" de Florianópolis: impasses e perspectivas para a 'base de pantera'. Florianópolis: UFSC/CFH/NUPPE, 2010. P. 133-153.

PASINATO, Wania. Consultoria para realização de Diagnóstico sobre as Delegacias Especializadas de Atendimento a Mulher/DEAMS nas regiões Sudeste e Centro-Oeste. - Relatório. São Paulo: Projeto Segurança Cidadã. Programa das Nações Unidas para o Desenvolvimento e Secretaria Nacional de Segurança Pública do Ministério da Justiça/SENASP, 2013.

PASINATO, Wania; SANTOS, Cecília MacDowell. Mapeamento das Delegacias da Mulher no Brasil. Campinas: Núcleo de Estudos de Gênero Pagu/Unicamp/Ceplaes/IDRC, 2008. Disponível em: http:/ /www.observe.ufba.br/_ARQ/bibliografia/MAPEO_Brasil[1].pdf. Acesso em10/03/2018.

POLÍCIA CIVIL DO ESTADO DE SANTA CATARINA. Resolução n. 008/GAB/CPC/SSP/2013 de 07 de outubro de 2013. Dispõe sobre as competências das Delegacias de Polícia da Mulher, da Criança e do Adolescente, bem como dá outras providências. Disponível em: http://www.doe.sea.sc.gov.br/ Repositorio/20131014/Materias/145333/145333.html. Acesso em 10/03/2018.

SANTA CATARINA. Lei Complementar n.453, de 5 de agosto de 2009. Institui o Plano de Carreira do Grupo Segurança Pública - Polícia Civil. Disponível em: http://www.portaldoservidor.sc.gov.br/ ckfinder/userfiles/arquivos/Legislacao\%20Correlata/Leis\%20Complementares/2009__LEI_COMPLEMENTAR_N\%C2\%BA_453\%2C_de_05_de_agosto_de_2009.pdf. Acesso em 22/0̄// $\overline{201 \overline{8}}$. 
SANTA CATARINA. Decreto $n^{\circ} 1.277$, de 30 de outubro de 2012. Dispõe que unidades policiais localizadas em regiões de fronteira passem a receber nova denominação. Disponível em http:// server03.pge.sc.gov.br/LegislacaoEstadual/2012/001227-005-0-2012-005.htm.

SECRETARIA NACIONAL DE POLítICAS PARA AS MULHERES. Ligue 180. Brasília: Ministério dos Direitos Humanos/Centro Cultural Banco do Brasil (CCBB), 2016.

WAISELFISZ, Julio Jacobo. Mapa da Violência 2015: Homicídio de mulheres no Brasil. FLACSO (Faculdade Latino-Americana de Ciências Sociais): Brasília, 2015. Disponível em: https:// www.mapadaviolencia.org.br/mapa2015_mulheres.php

Ana Claudia Delfini Capistrano de Oliveira (iD) 0000-0002-7154-9020

Doutora em Sociologia pela Universidade Federal de Santa Catarina

Graduada em História pela Universidade Federal de Santa Catarina (1995), mestre em Sociologia pela mesma universidade. Professora titular da Universidade do Vale de Itajaí, em Itajaí, nos cursos de Direito, Relações Internacionais, no Programa de Mestrado Profissional em Gestão de Políticas Públicas/PMGPP e no mestrado/doutorado em Educação/PPGE. Tem experiência na área de Sociologia da Infância, Juventude e Políticas Públicas de Gênero. Coordenou os projetos de extensão "Programa de Formação em Cidadania Infanto-juvenil" e "Observatório de políticas públicas" entre 2004 a 2016. Participa dos Grupos de Pesquisa/CNPq "Dinâmicas Institucionais das Políticas Públicas" do PMGPP e "Educação e Trabalho", do PPGE. Integrante da Rede Internacional RED HILA: "Red Iberoamericana en Ciencias Sociales con enfoque de género", com sede na Colômbia, desde 2014. É coordenadora do Grupo de Pesquisa/CNPq: "Sociologia da infância, relações de gênero e políticas públicas" desde 2006 e representante da Universidade do Vale de Itajaí no Conselho Municipal dos Direitos da Mulher em Itajaí.

Universidade do Vale do Itajaí, Programa de Mestrado em Gestão de Políticas Públicas e Programa de Mestrado e Doutorado em Educação

Rua Uruguai 458 , Centro

88302-901 - Itajaí, SC, Brasil

$47-33417847$

anaclaudia.univali@gmail.com

Ana Silvia Serrano Ghisi (iD 0000-0002-8658-2544

Mestre em Gestão de Políticas Públicas pela Universidade do Vale do Itajaí

Possui graduação em Direito pela Universidade Federal de Santa Catarina, Especialização em Direito Penal e Processual Penal e Especialização em Polícia Comunitária. Tem experiência na área de Direito Público, ałuando principalmente nos seguintes temas: Segurança Pública, Gênero e Políiticas Públicas, Direito Penal, Direito Administrativo, Direitos Humanos e Polícia Comunitária. É delegada de polícia da Polícia Civil de Santa Catarina, atuando junto ao Setor de Gestão de Pessoas e Professora titular dos cursos de formação inicial e de pós-graduação da Academia de Polícia Civil de Santa Catarina, Brasil.

Secretaria de Segurança Pública do Estado de Santa Catarina, Delegacia Geral da Polícia Civil de Santa Catarina

Av. Governador Ivo Silveira, 1521. Capoeiras,

$88050-000$ - Florianópolis - SC- Brasil

(48) $3665-8100$

aninha37@gmail.com 


\section{COMO CITAR ESSE ARTIGO DE ACORDO COM AS NORMAS DA REVISTA}

OLIVEIRA, Ana Cláudia Delfini Capistrano de; GHISI, Ana Silvia Serrano. "Norma Técnica de Padronização e as Delegacias das Mulheres em Santa Catarina". Revista Estudos Feministas, Florianópolis, v. 27, n. 1, e46855, 2019.

\section{CONTRIBUIÇÃO DE AUTORIA}

Ana Claudia Delfini Capistrano de Oliveira - Declaro que, como autora, contribui na concepção e desenho da pesquisa, desde a sua elaboração, coleta e análise dos dados que resultaram nas discussões dos resultados para o recorte analítico do presente artigo. Declaro, ainda, que participei ativamente na elaboração, revisão e aprovação da versão final submetida a esta revista.

Ana Silvia Serrano Ghisi - Declaro que, como autora, contribui na concepção e desenho da pesquisa, desde a sua elaboração, coleta e análise dos dados que resultaram nas discussões dos resultados para o recorte analítico do presente artigo. Declaro, ainda, que participei ativamente na elaboração, revisão e aprovação da versão final submetida a esta revista.

\section{FINANCIAMENTO}

Não se aplica

CONSENTIMENTO DE USO DE IMAGEM

Não se aplica

APROVAÇÃO DE COMITÊ DE ÉTICA EM PESQUISA

Não se aplica

\section{CONFLITO DE INTERESSES}

Declaramos que não há conflitos de interesse de nenhuma ordem, nem financeiros, pessoais, ou entre possíveis revisores e editores com possíveis vieses temáticos.

\section{LICENÇA DE USO}

Este artigo está licenciado sob a Licença Creative Commons CC-BY. Com essa licença você pode compartilhar, adaptar, criar para qualquer fim, desde que atribua a autoria da obra.

\section{HISTÓRICO}

Recebido em 23/09/2016

Reapresentado em 04/05/2018

Reapresentado em 20/06/201 8 com novo título

Aprovado em 21/06/2018

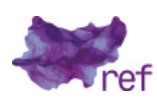

